\title{
Application of a physics-based lumped parameter model to evaluate reservoir parameters during $\mathrm{CO}_{2}$ storage
}

\author{
Samin Raziperchikolaee ${ }^{1}$ (D) Srikanta Mishra ${ }^{1}$
}

Received: 5 March 2020 / Accepted: 5 August 2020 / Published online: 14 August 2020

(c) The Author(s) 2020

\begin{abstract}
Evaluating reservoir performance could be challenging, especially when available data are only limited to pressures and rates from oil field production and/or injection wells. Numerical simulation is a typical approach to estimate reservoir properties using the history match process by reconciling field observations and model predictions. Performing numerical simulations can be computationally expensive by considering a large number of grids required to capture the spatial variation in geological properties, detailed structural complexity of the reservoir, and numerical time steps to cover different periods of oil recovery. In this work, a simplified physics-based model is used to estimate specific reservoir parameters during $\mathrm{CO}_{2}$ storage into a depleted oil reservoir. The governing equation is based on the integrated capacitance resistance model algorithm. A multivariate linear regression method is used for estimating reservoir parameters (injectivity index and compressibility). Synthetic scenarios were generated using a multiphase flow numerical simulator. Then, the results of the simplified physicsbased model in terms of the estimated fluid compressibility were compared against the simulation results. $\mathrm{CO}_{2}$ injection data including bottom hole pressure and injection rate were also gathered from a depleted oil reef in Michigan Basin. A field application of the simplified physics-based model was presented to estimate above-mentioned parameters for the case of $\mathrm{CO}_{2}$ storage in a depleted oil reservoir in Michigan Basin. The results of this work show that this simple lumped parameter model can be used for a quick estimation of the specific reservoir parameters and its changes over the $\mathrm{CO}_{2}$ injection period.
\end{abstract}

Keywords $\mathrm{CO}_{2}$ storage $\cdot$ Physics-based model $\cdot$ Lumped parameter model $\cdot$ Capacitance resistance approach $\cdot$ Multivariate linear regression $\cdot$ Injectivity index $\cdot$ Depleted oil reef $\cdot$ Michigan Basin

\section{Introduction}

Storage of carbon dioxide into geological formations is a mitigation strategy to reduce mankind's greenhouse gas emissions into the atmosphere. Depleted oil and gas reservoirs, saline formations, and coal seams could be used as potential $\mathrm{CO}_{2}$ storage sites (Bachu et al. 2007; Gale 2004). Among them, depleted oil reservoirs are considered a promising candidate for injection and long-term storage of carbon dioxide due to its capability to achieve two objectives simultaneously: (1) enhanced oil recovery (EOR) and (2) $\mathrm{CO}_{2}$ storage during and after EOR (Alvarado and Manrique 2010).

Samin Raziperchikolaee raziperchikolae@battelle.org

1 Battelle Memorial Institute, Columbus, OH, USA
Assessing environmental risks associated with the geological $\mathrm{CO}_{2}$ sequestration is necessary to verify long-term safe storage of $\mathrm{CO}_{2}$ (Gale 2004; Rubin and De Coninck 2005). In the context of $\mathrm{CO}_{2}$ sequestration, different types of risks have been identified including site performance risk, containment risks associated with $\mathrm{CO}_{2}$ and brine leakage, and public reception risk (Pawar et al. 2015; Rubin and De Coninck 2005). During $\mathrm{CO}_{2}$ storage, dynamic reservoir parameters (the reservoir parameters varying with time such as pore pressure) should be evaluated since they affect the safety of the potential sequestration site (Bachu et al. 2007; Bradshaw et al. 2007; Fang et al. 2012; Raziperchikolaee et al. 2013).

Numerical modeling can be used as a tool to evaluate the changes in reservoir parameters, estimate storage capacity, and injectivity of the reservoir during $\mathrm{CO}_{2}$ storage and eventually ensure safety of the $\mathrm{CO}_{2}$ storage in the depleted reservoirs (Bissell et al. 2011; Delshad et al. 2013; Kano and Ishido 2011; Kumar et al. 2005; Nghiem et al. 2009; 
Raziperchikolaee et al. 2013, 2019). Analytical solutions have also been developed to estimate changes of reservoir behavior (such as pressure buildup by $\mathrm{CO}_{2}$ injection and poroelastic effect of injection) and provide a quick risk assessment tool for $\mathrm{CO}_{2}$ storage process (Mathias et al. 2010; Nordbotten and Celia 2010; Nordbotten et al. 2005; Okwen et al. 2010; Oruganti and Mishra 2013; Raziperchikolaee and Mishra 2019b, 2020). Analytical methods are typically limited to simpler scenarios such as sharp boundary between different phases with no mass transfer between phases (Mathias et al. 2010; Nordbotten and Celia 2010; Nordbotten et al. 2005; Okwen et al. 2010). Numerical simulations generally require a large number of grid blocks since gridding of the different rock types in a caprock-reservoir system is necessary. Also, a combination of multiple equations representing different fluid components or phases should be solved numerically. In addition, numerical simulations typically should be run in several time steps to model different oil recovery periods including primary production, secondary water-flood, tertiary $\mathrm{CO}_{2} \mathrm{EOR}$, and eventually $\mathrm{CO}_{2}$ storage period. Therefore, numerical simulations would be computationally expensive specifically for the complicated system including three phases in a reservoir with a complex structure during different recovery periods (Bissell et al. 2011; Li et al. 2019; Uddin et al. 2013).

The alternative method, presented in this study, is based on a simplified physics-based lumped parameter modeling approach to study fluid flow behavior of a depleted oil reservoir during $\mathrm{CO}_{2}$ storage. The advantages of this approach are that it requires fewer data sets to build the model and less computation time. The previous studies showed the application of CRM algorithm (As an example of simplified methods) to evaluate reservoir performance for waterflooding (Bastami et al. 2012a; Mamghaderi et al. 2013), EOR including $\mathrm{CO}_{2}$ EOR (Eshraghi et al. 2016; Lake et al. 2007; Nguyen 2012; Sayarpour 2008) and inter-well connectivity (Albertoni and Lake 2003; Gözel 2015; Yousef et al. 2006). This work focuses on the $\mathrm{CO}_{2}$ storage process (no production stage) using a simplified version of CRM fitting the objective. Also, the previous works mainly investigated the theoretical aspects of capacitance resistance-based models and comparison of the CRM results with the synthetic simulation results (Bastami et al. 2012b; Salehian and Soleimani 2018; Sayarpour et al. 2009b). However, capacitance resistance-based models to evaluate reservoir performance using field data were presented in limited studies mainly for waterflooding (Mamghaderi et al. 2013; Nguyen et al. 2011a, 2011b; Sayarpour et al. 2009a; Temizel et al. 2018Wang et al. 2011). In this work, we not only studied a comparison between a simplified CRM algorithm and the simulation results of the synthetic cases, but also investigated CRM application to evaluate reservoir performance using field data of $\mathrm{CO}_{2}$ storage project with long-term $\mathrm{CO}_{2}$ injection using field monitoring data. As a result, the methodology and results of this work could be used as a guide for $\mathrm{CO}_{2}$ storage operators to quickly evaluate the reservoir performance during storage.

In this work, we describe the governing equations based on which a simplified physics-based model will be developed to establish a relationship between the well data (i.e., BHP and injected volume) and limited reservoir parameters (i.e., initial reservoir pressure) at first. Then, the fitted parameters, injectivity index, and reservoir fluid compressibility will be estimated. The fitted parameters can then be used for evaluating the fluid flow behavior of the reservoir during injection. The response of a synthetic numerical model will be evaluated using the developed model for verifying the simplified approach. Finally, a field application of the simplified physics-based model for $\mathrm{CO}_{2}$ storage into a depleted oil reef in the Michigan Basin will be discussed. Compositional numerical simulations have been previously performed to simulate reservoir behavior in different production periods including primary production, $\mathrm{CO}_{2}$-EOR, and eventually $\mathrm{CO}_{2}$ storage for selected carbonated reefs in the Michigan Basin (Ganesh et al. 2014; Gupta et al. 2015). The uncertainties associated with history matching could be due to (1) the complexity of reef structure specifically in the reefs with multiple lobes and lack of field data to depict the reef structure, (2) the presence of different facies in the carbonate reef having different geological properties (porosity, permeability), (3) diagenesis process in carbonate reef that add uncertainty regarding spatial distribution of geological properties, and (4) lack of sufficient rock and fluid properties measurement (e.g., relative permeability) to reduce the number of calibration parameters during history matching. In addition, the history match process could be computationally expensive by considering several uncertain parameters for the matching process using numerical simulations. In this case, a simplified physics-based method could be considered as a quick efficient approach to predict specific reservoir parameters (compared to a detailed prediction of reservoir parameters using numerical simulation) during $\mathrm{CO}_{2}$ injection that could be useful from an operational point of view.

\section{Modeling approach}

A capacitance-resistance-based model is used to describe the physics of $\mathrm{CO}_{2}$ injection and develop the physicsbased model. The capacitance resistance model (CRM) is an input-output model that can quantify the relationship between injectors, producers, and reservoir properties (Kim et al. 2012; Lake et al. 2007; Sayarpour 2008; Sayarpour et al. 2009a, 2009b; Weber et al. 2009). As documented in these references, CRM has been applied to predict reservoir parameters during primary and secondary recovery using 
oil field data including the fields with many wells. CRM has been developed based on the hypothesis that reservoir characteristics can be estimated mainly from production and injection well data (Bastami et al. 2012b). The CRM takes operational data (flow rate and BHP data) to perform history match of injection/production data (Bastami et al. 2012b). The model is derived from the continuity equation which assumed that there is no aquifer and the total compressibility of reservoir is constant. The model is described as follows (Nguyen et al. 2011a):

$C_{\mathrm{t}} V_{\mathrm{p}} \frac{\mathrm{d} P}{\mathrm{~d} t}=-q$

where $P$ is the average reservoir pressure, $q$ is the flow rate (assumed positive for production), $C_{\mathrm{t}}$ is the fluid total compressibility, and $V_{\mathrm{p}}$ is the reservoir pore volume. Assuming $C_{\mathrm{t}} V_{\mathrm{p}}$ is constant over the period from 0 to $t$, Eq. 1 then becomes:

$C_{\mathrm{t}} V_{\mathrm{p}}(P(t)-P(0))=-N_{\mathrm{p}}(t)$

where $N_{\mathrm{p}}$ is total production in case of primary oil recovery. Equation 2 is mainly developed for the primary production of an oil field. The equation can be simply modified to be used for the injection into an oil reservoir instead of production from the reservoir. By substituting injectivity index into Eq. 2, the equation will be:

$-N_{\mathrm{i}}(t)=\frac{C_{\mathrm{t}} V_{\mathrm{p}}}{J} q(t)+C_{\mathrm{t}} V_{\mathrm{p}} P_{\mathrm{bh}}(t)-C_{\mathrm{t}} V_{\mathrm{p}} P_{0}$

$J=\frac{q}{P_{\mathrm{bh}}-P}$

where $P_{0}$ is the initial reservoir pressure, $P_{\mathrm{bh}}$ is bottom hole pressure, $N_{\mathrm{i}}$ is cumulative injected volume, and $\mathrm{J}$ is the injectivity index measuring of the ability of a well to accept fluids. Equation 3 is true for a reservoir with only one well, but it can also be applied to a reservoir with multiple wells. In this case, a reservoir with multiple wells is automatically divided by pressure boundaries into multiple compartments, each containing a single well. As fluid in a reservoir moves away from injector, the boundaries will be created between the injectors. As a result, it can be applied to the reservoir system with multiple injector wells in different compartments similar to the carbonate reef system in Michigan Basin (Fig. 1). In such system, each reef contains multiple compartments (lobes).

A multivariate linear model can be used for estimating specific reservoir parameters using Eq. 3. The linear model is defined as a sum of linear and constant terms between the input parameters (i.e., injection rate, bottom hole pressure, and initial pressure). The response vector is the cumulative

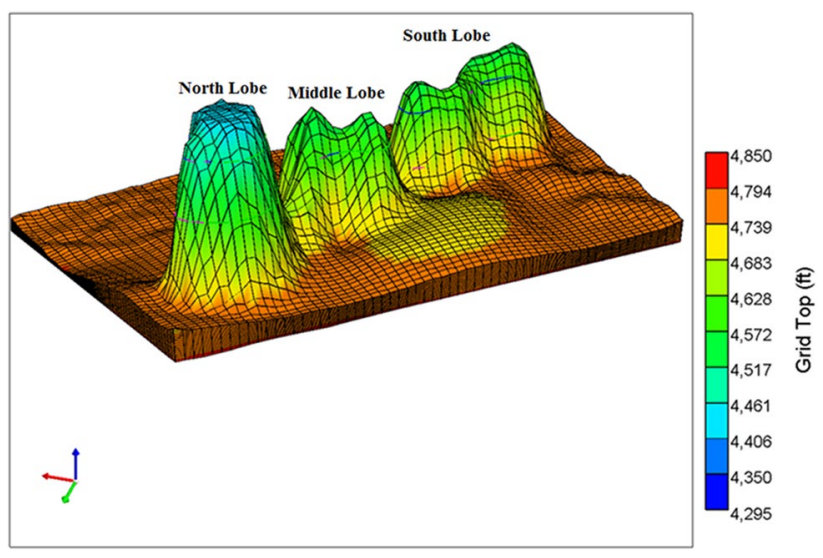

Fig. 1 Example of a reservoir (a reef with multiple connected lobes) with injection into different connected lobes

injected volume $N_{\mathrm{i}}$. The approximating function, $\widehat{N}_{\mathrm{i}}$, is defined by:

$\widehat{N}_{i}=\sum_{i=1}^{2} b_{i} x_{i}=C_{\mathrm{t}} V_{\mathrm{p}} \times\left(\frac{1}{J} q(t)+P_{\mathrm{bh}}(t)-P_{0}\right)$

where $\widehat{N}_{\mathrm{i}}$ represents predicted response parameter, $x_{1}$ and $x_{2}$ represent $q(t)$ and $P_{\mathrm{bh}}(t)-P_{0}$. The coefficients including inverse of injectivity index $(1 / J)$ and total compressibility times pore volume $\left(C_{\mathrm{t}} V_{\mathrm{p}}\right)$ are estimated so as to minimize the mean squared difference between the prediction vector $\widehat{\left(N_{i}\right)}$ and the true response vector $\left(N_{i}\right)$. R-squared, which is defined as the amount of variation in the response that is explained by the predictors, is used to measure the accuracy of model prediction. If the initial reservoir pressure is treated as unknown, it becomes another parameter to be estimated. If the total system compressibility is known, then the pore volume can be calculated for different time intervals resulting in a series of estimated pore volumes over time.

\section{Results}

\section{Comparison with the synthetically generated data}

A compositional simulator (CMG-GEM 2012) was used to conduct the modeling for this study and generate synthetic numerical data. CMG-GEM can simulate $\mathrm{CO}_{2}$ behavior in subsurface reservoirs by solving one equation describing thermodynamic equilibrium between oil and gas phases. Chemical reactions between $\mathrm{CO}_{2}$ and other components in the system were not modeled in this study. The model was isothermal. Key features of the models are as follows: (1) the model grids are rectangular Cartesian grids with uniform vertical and lateral grid size; (2) a single $\mathrm{CO}_{2}$ injection well

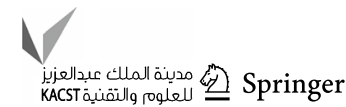


is located in the grid system center; (3) rock properties do not vary in the lateral or vertical; (4) oil composition and the following oil pressure, volume, and temperature (PVT) properties are similar to the light oil reservoirs of Appalachian Basin (Raziperchikolaee and Mishra 2019a); and (5) the model is closed boundary. The oil PVT parameters are listed in Table 1. The model schematic is shown in Fig. 2. Equation 2 was used to obtain the simplified physics-based model fitted parameters. A synthetic numerical model, initially fully oil saturated above the bubble point pressure, was developed to predict the total fluid compressibility. These predictions were then compared to those estimated using the simplified physics-based model. Table 1 summarizes the model parameters. The simulation results show that the total fluid compressibility of oil-saturated system will be $1.32 \mathrm{E}-5(1 / \mathrm{psi})$ at the end of 5 years injection. The reason for decreasing compressibility is pressure increasing. Increasing pressure leads to lower compressibility of oil. Also, $\mathrm{CO}_{2}$ is in the supercritical state with density of $42.7 \mathrm{lbm} /$ $\mathrm{ft}^{3}$. Simplified physics-based model is also used to calculate the compressibility of the system. A linear regression model (using Eq. 2) was applied to estimate fluid compressibility as well. Figure 3 shows the plot of $\mathrm{CO}_{2}$ injection volume versus average reservoir pressure for the oil-saturated system. It shows the total compressibility times pore volume of 171 (bbl/psi), leading to the total compressibility of $1.41 \mathrm{E}-5$ (1/ psi), which is in good agreement with simulation prediction.

Using CRM algorithms, estimates of reservoir performance are primarily a function of well data (i.e., BHP and injected volume). While the heterogeneity of geological properties can affect reservoir performance, their effect is incorporated indirectly in input well data (such as BHP). Previous simulation studies using synthetic cases show that CRM is able to estimate reservoir performance in both homogenous and heterogeneous reservoirs (Nguyen 2012; Sayarpour et al. 2009b). We also did three additional

Table 1 Essential input parameters of the simulation synthetic case

\begin{tabular}{ll}
\hline Parameter & Value \\
\hline Initial pressure for oil saturated & $2000 \mathrm{psi}$ \\
Injector BHP for oil-saturated reservoir & $5000 \mathrm{psi}$ \\
Porosity & 0.05 \\
Permeability & $50 \mathrm{mD}$ \\
Model dimension & $2500 \times 2500 \times 218.3 \mathrm{ft}$ \\
Model grid numbers & $21 \times 21 \times 7$ \\
Reservoir pore volume & $1.21 \mathrm{E} 7 \mathrm{bbl}$ \\
Initial compressibility for oil-saturated model & $1.78 \mathrm{E}-51 / \mathrm{psi}$ \\
Oil bubble point pressure $\left(P_{\mathrm{b}}\right)$ & $1300 \mathrm{psi}$ \\
Oil formation volume factor at $P_{\mathrm{b}}$ & $1.15 \mathrm{bbl} / \mathrm{STB}$ \\
Solution oil-to-gas ratio at $P_{\mathrm{b}}$ & $350 \mathrm{SCF} / \mathrm{STB}$ \\
Injection time & 5 years \\
\hline
\end{tabular}

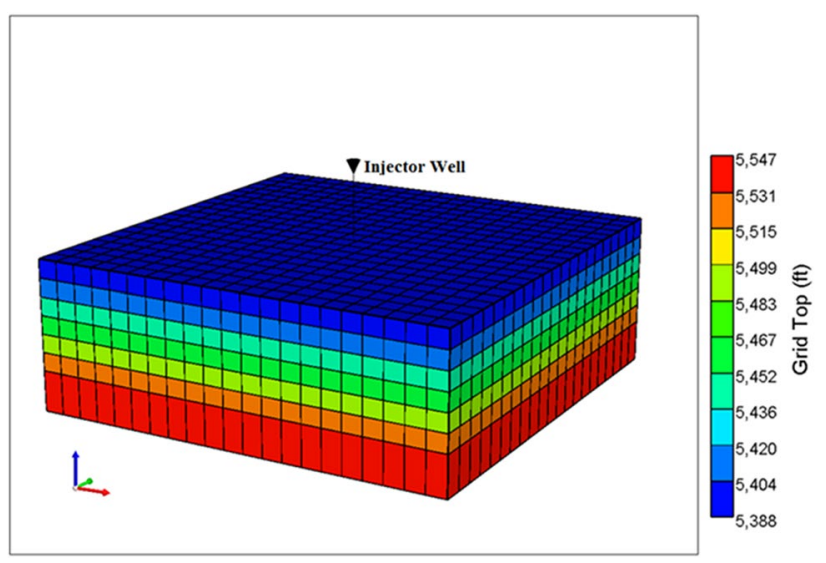

Fig. 2 Model schematic for simulation of synthetic case

simulations in which permeability and porosity of the inner zone increased to twice of initial values to represent hypothetical heterogeneous scenarios. Figure 4 shows the model's map view with a higher permeability/porosity zone in the middle of the model. The heterogeneous zone is expanding in the model (as shown in Fig. 4) with case 1 having the smallest zone and case 3 having the largest zone. The simplified physics-based model is also used to calculate the compressibility of the system. Figure 5 shows the plot of cumulative injected $\mathrm{CO}_{2}$ versus average pressure for three additional cases using numerical simulation and applied linear regression (based on Eq. 2). Note that the pore volume of the system changes as porosity changes. The pore volume of the models would be $1.23 \mathrm{E}+7$ for case $1,1.27 \mathrm{E}+7$ for case 2 , and $1.34 \mathrm{E}+7(\mathrm{bbl})$ for case 3 by expanding the inner zone size. The total compressibility times pore volume of 173 , 179, and 190 (bbl/psi) using Eq. 2 leads to total compressibility of $1.40 \mathrm{E}-5,1.41 \mathrm{E}-5$, and $1.41 \mathrm{E}-5(1 / \mathrm{psi})$, for the three additional cases. The simulation results show that the

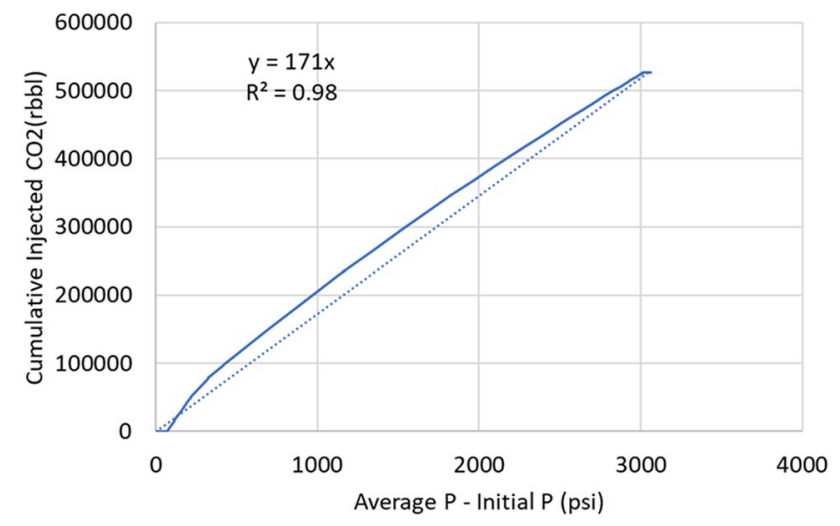

Fig. 3 Predicted cumulative injected $\mathrm{CO}_{2}$ versus average pressure for oil-saturated reservoir using numerical simulation and applied linear regression using Eq. 2 


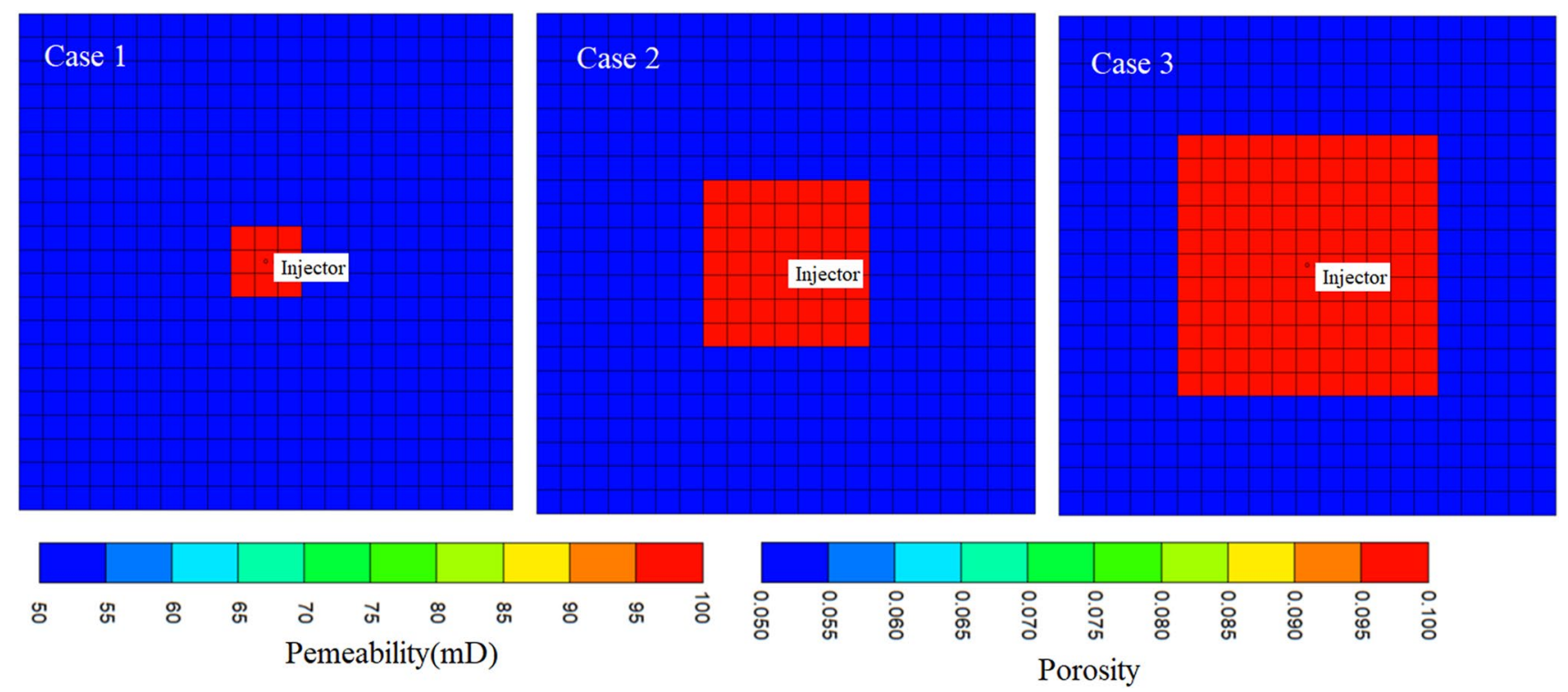

Fig. 4 Map view of three additional cases with expanding size of higher porosity and permeability zones with case 1 having smallest zone and case 3 having largest zone
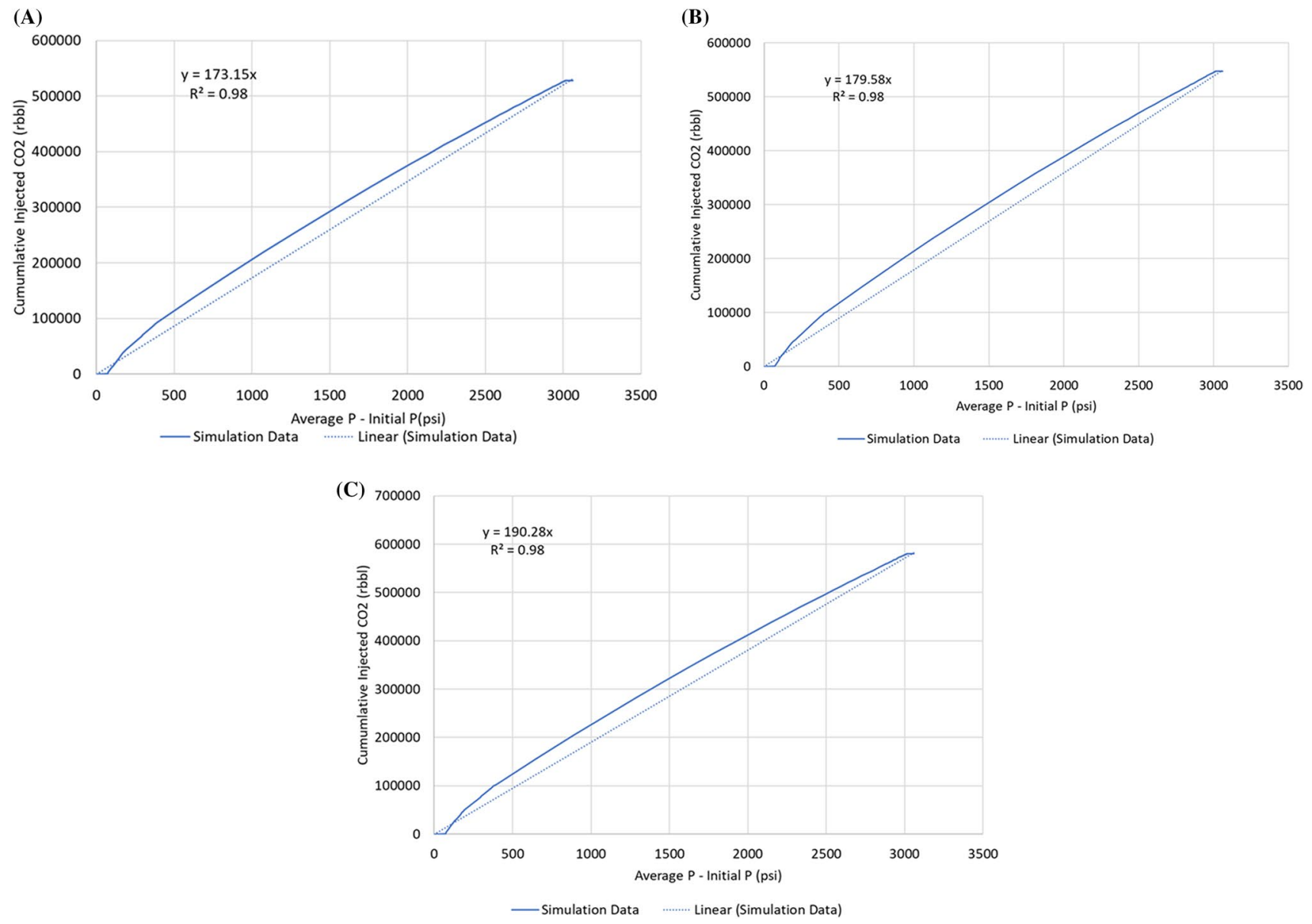

Fig. 5 Predicted cumulative injected $\mathrm{CO}_{2}$ versus average pressure for oil-saturated reservoir using numerical simulation and applied linear regression using Eq. 2 for a Case 1, b Case 2, and $\mathbf{c}$ Case 3 
total fluid compressibility of the heterogeneous systems will be close to each other $(1.3 \mathrm{E}-5(1 / \mathrm{psi}))$ and the homogenous case scenario (presented previously) at the end of 5 years injection. Note that although saturation of different phases varied in the model through incorporating different permeability/porosity for each zone, the total fluid compressibility in the whole system would remain similar to each other and the homogenous case.

\section{Estimating reservoir parameters for $\mathrm{CO}_{2}$ storage into a depleted oil field}

\section{Oil field description}

Carbonate reefs in the Northern Pinnacle Reef Trend are significant hydrocarbon reservoirs in the Michigan Basin (Rine et al. 2015). Approximately, 800 such reefs have been mapped and drilled in the Northern Pinnacle Reef Trend of the Michigan Basin (Miller et al. 2014). Such reefs have typically undergone primary production and, in some cases, secondary recovery (Grammer et al. 2009). $\mathrm{CO}_{2}$ has been injected into a small number of reefs which has the potential capacity for supporting $\mathrm{CO}_{2}$ sequestration (Coniglio et al. 2004; Kelley et al. 2014). Some reefs have only one lobe, while others have multiple lobes. The Brown Niagaran formation is the main oil producing reservoir of the reef system (Catacosinos et al. 2000; Haagsma et al. 2017; Huh 1974; Riley et al. 2010). The production mechanism was solution gas drive during primary production (no aquifer drive).

The carbonate reef, used in this study, is located in Otsego County, Michigan. The reef comprises of three hydraulically connected lobes, (a) northern lobe comprising of one injection and two production wells, (b) middle lobe with one injection and one production well, and (c) southern lobe also having one injection and one production well. The middle and northern lobes are strongly connected. Primary production started in 1974 and stopped at the start of $\mathrm{CO}_{2}$ storage phase started in 2015. $\mathrm{CO}_{2}$ injection began in the reef with injection into the northern lobe on 12/14/2015 to build up the pressure in the reservoir. The middle lobe injection started later on 10/4/2016. Finally, the southern lobe injection started on $10 / 19 / 2017$. Since $\mathrm{CO}_{2}$ storage began, the reef has received a net of 566,437 metric tons of $\mathrm{CO}_{2}$ until 06/30/2019.

\section{Simplified physics-based model application to middle and southern lobe of the reef}

Data acquired from the injection well in the middle lobe of the reef were used as an input to the model. The data interval is shown in Fig. 6. The cross-plot of field versus predicted $\mathrm{CO}_{2}$ injection volume using the simplified physics-based model is shown in Fig. 7. The model was evaluated using

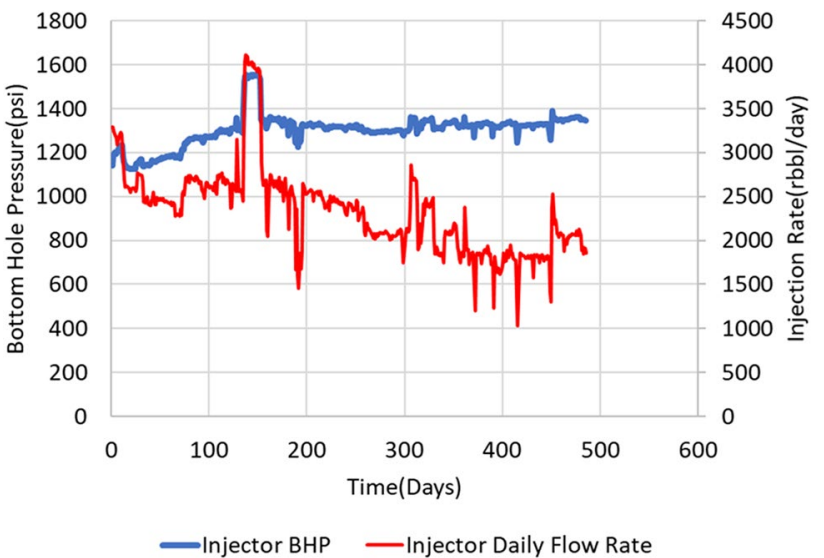

Fig. 6 BHP and $\mathrm{CO}_{2}$ injection rate for injection well in the middle lobe

the actual field values in y-axis and the predicted values in $\mathrm{x}$-axis. The fitted parameters, R-squared of the regression, and the 1:1 line for predicted versus actual data are also shown in Fig. 7. The model performance was evaluated using R-squared. As shown in Fig. 7, the R-squared for this model is 0.89 , showing that the simplified physics-based model is able to explain injection-related data and estimate fitted parameters ( $J$ and $\left.C_{\mathrm{t}} \times \mathrm{PV}\right)$ with high confidence. The initial pressure of $600 \mathrm{psi}$ is used as an input for the model to maximize the R-squared in the multivariate linear model. The total compressibility times pore volume of the model is $2727 \mathrm{rbbl} / \mathrm{psi}$, and the estimated injectivity index is 4.89 $\mathrm{rbbl} /($ day $\times \mathrm{psi})$ for the whole time period. Using material balance calculation, the estimated pore volume of the reef would be approximately $3,937,500 \mathrm{rbbl}$ for the middle lobe leading to fluid compressibility of $6.93 \mathrm{E}-04 \mathrm{1} / \mathrm{psi}$. This is consistent with the total fluid compressibility typical of the Michigan Basin oil reservoirs having a gas zone. Total fluid compressibility is defined as the sum of the compressibility of the fluids in the reservoir weighted by their saturation. A total compressibility of $7.54 \mathrm{E}-51 / \mathrm{psi}$ would be expected based on an average water saturation of 0.2 , oil saturation of 0.55 , and gas saturation of 0.25 , using water compressibility of $3.1 \mathrm{E}-61 / \mathrm{psi}$, oil compressibility of $5.16 \mathrm{E}-41 / \mathrm{psi}$, and gas compressibility of $1.88 \mathrm{E}-31 / \mathrm{psi}$ at reservoir pressure of 1000 psi. The value of water, oil, and gas compressibility can be estimated from laboratory PVT measurements or calculated from correlations. Water compressibility is a weak function of pressure, temperature, and salinity. Meehan correlation (Meehan 1980) is used to calculate water compressibility. BWR equation of state (Board 1979) is used to calculate gas compressibility. Vasquez and Beggs correlation (Vazquez and Beggs 1977) is used to calculate oil compressibility. The oil and gas compressibility are calculated using the gas-specific gravity of 0.67 and oil gravity of 45 API (similar to the ones in Michigan Basin reservoirs). 
(A)

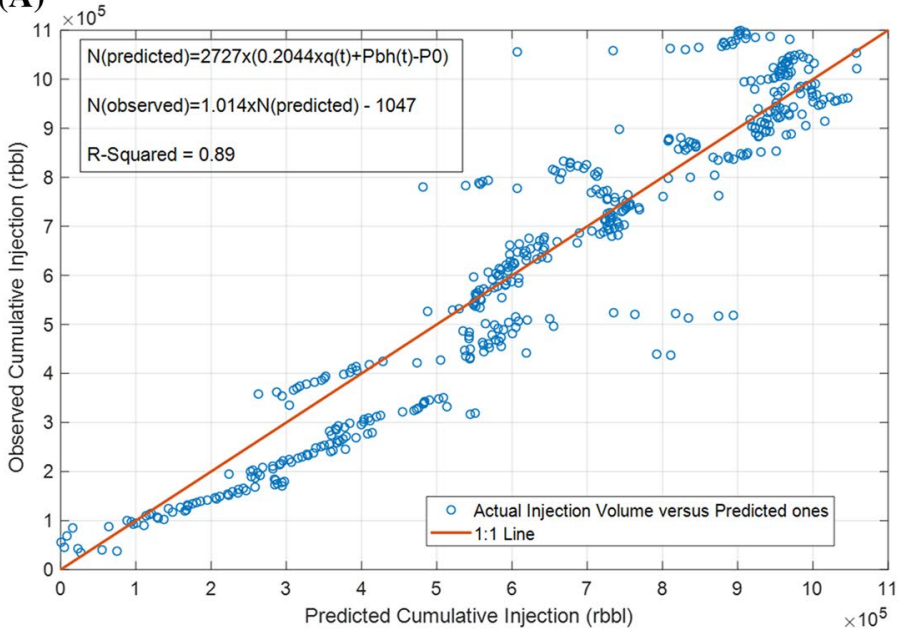

(B)

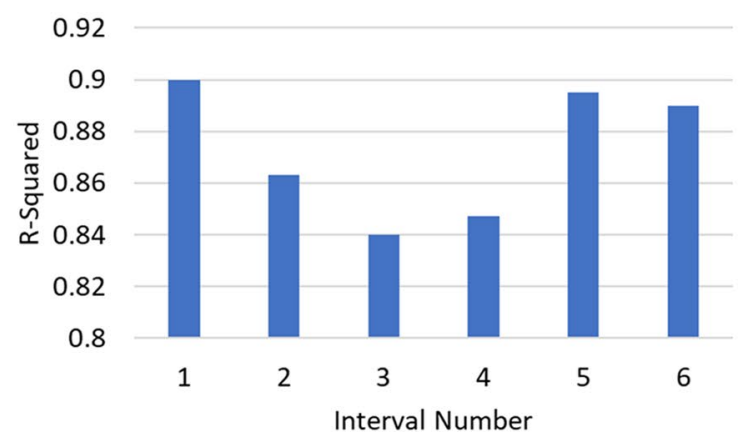

Fig. 7 a Actual (field) $\mathrm{CO}_{2}$ injection volume versus fitted data using simplified physics-based model for middle lobe and the 1:1 line for predicted versus actual data. b Estimation of R-squared in different

There is a concurrent injection into the northern lobe at the same time of $\mathrm{CO}_{2}$ injection into the middle lobe. As a result, the pressure of the middle lobe is affected by the pressure in the northern lobe since both lobes are connected. This does not affect the prediction of fitted parameters using the simplified physics-based model. Using the model, a reservoir is automatically divided by pressure boundaries into multiple compartments, each containing a well. As $\mathrm{CO}_{2}$ in a reservoir flows away from different injectors, the movement to different directions will create boundaries between the injectors.

The injection data for the middle lobe are divided into six time intervals which are increasing until it covers all injection data. Time intervals include 80, 160, 240, 320, 400 , and 480 days. For each fitting window, pore volumes times compressibility was estimated. These estimated pore volumes are the dynamic pore volumes that characterize the effective storage volume over different time intervals. As shown in Fig. 7, the pore volumes multiplied by the compressibility are increasing since the boundary of the reservoir is expanding by injection. Similarly, we
(C)

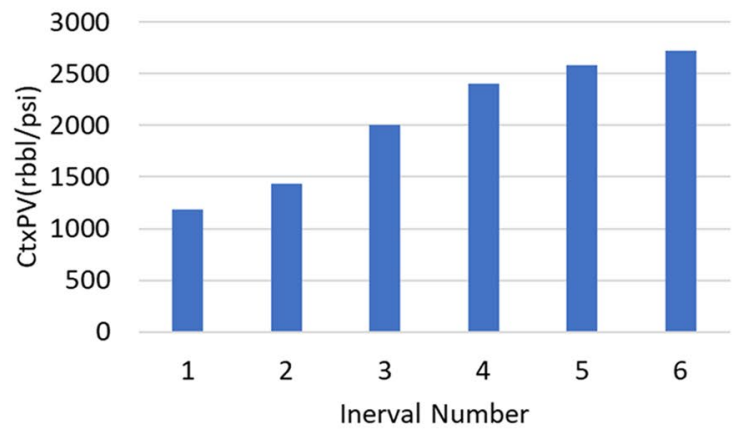

(D) 5.5

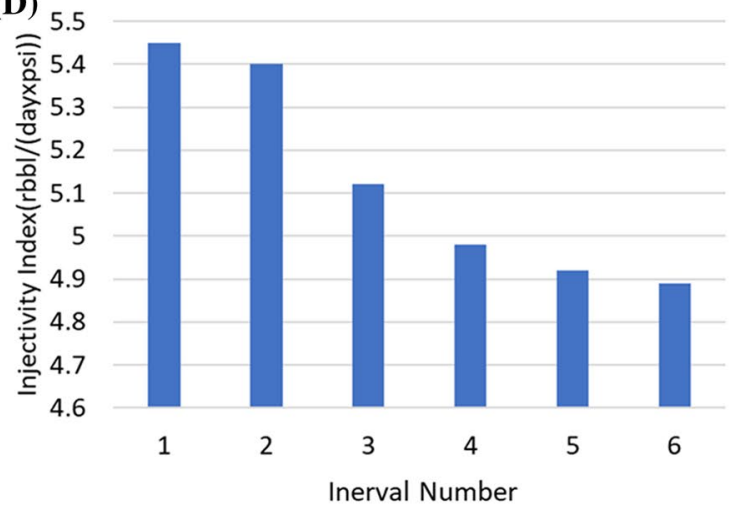

time intervals. $\mathbf{c}$ Estimation of pore volume $\times$ compressibility in different time intervals. d Estimation of injectivity index in different time intervals

estimated a series of injectivity indexes over different fitting windows. Injectivity index decreases gradually over the injection period of 480 days.

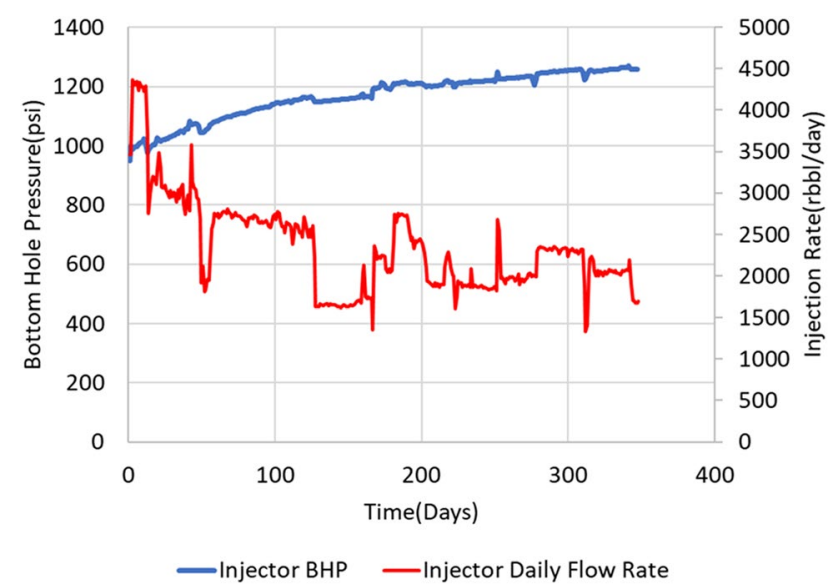

Fig. 8 BHP and $\mathrm{CO}_{2}$ injection rate for injection well in south lobe 


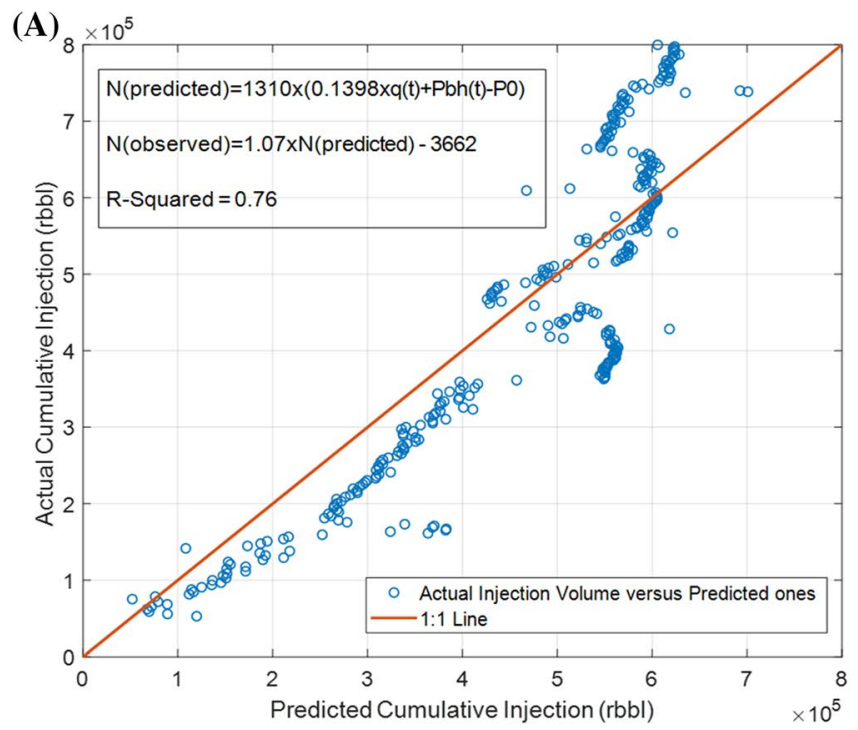

(B)

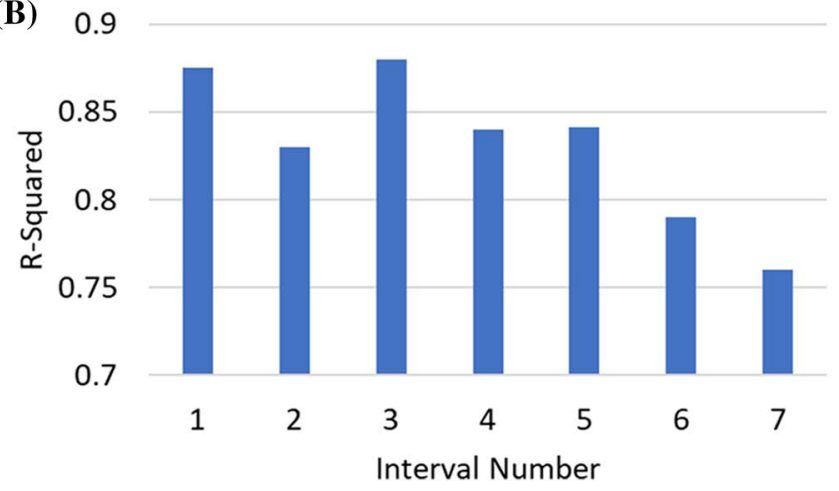

Fig. 9 a Actual (field) $\mathrm{CO}_{2}$ injection volume versus fitted data using simplified physics-based model for south lobe and the 1:1 line for predicted versus actual data. b Estimation of R-squared in different

$\mathrm{CO}_{2}$ injection data for the southern lobe of the reef were also used to predict reservoir performance. The data interval is shown in Fig. 8. As shown in Fig. 9, the R-squared for this model is 0.76 for the whole time period of injection. The total compressibility times pore volume of the model is $1310 \mathrm{rbbl} /$ $\mathrm{psi}$, and the estimated injectivity index is $7.15 \mathrm{rbbl} /($ day $\times \mathrm{psi})$. Using material balance calculation, the estimated pore volume of the reef would be approximately $1,968,750$ rbbl for the middle lobe leading to fluid compressibility of $6.65 \mathrm{E}-04$ $1 / \mathrm{psi}$. This is consistent with the total compressibility typical of the Michigan Basin oil reservoir with a separated gas zone ( 7.54E-5 1/psi). The injection data for the southern lobe are divided into six time intervals including 50, 150, 200, 250,
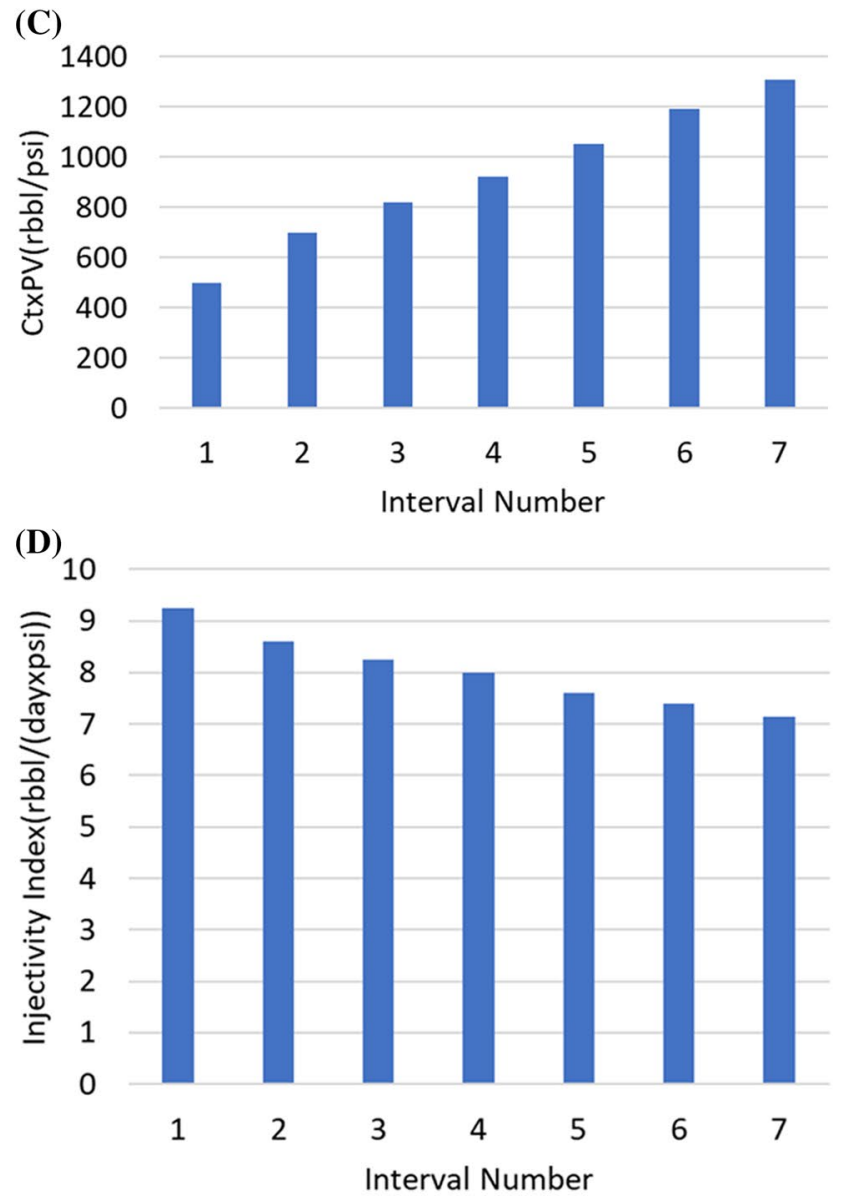

time intervals. c Estimation of pore volume $\times$ compressibility in different time intervals. d Estimation of injectivity index in different time intervals
300, and 350-day intervals. As shown in Fig. 9, the pore volumes times compressibility is increasing since the boundary of reservoir is expanding by injection. Injectivity index decreases gradually over the injection period of 350 days.

\section{Discussion: comparing field derived and estimated injectivity index in southern lobe}

We estimated the injectivity index using available field data for two time intervals (0-50 days and 200-250 days) of the southern lobe. Figure 10 shows the time interval and 
(A)

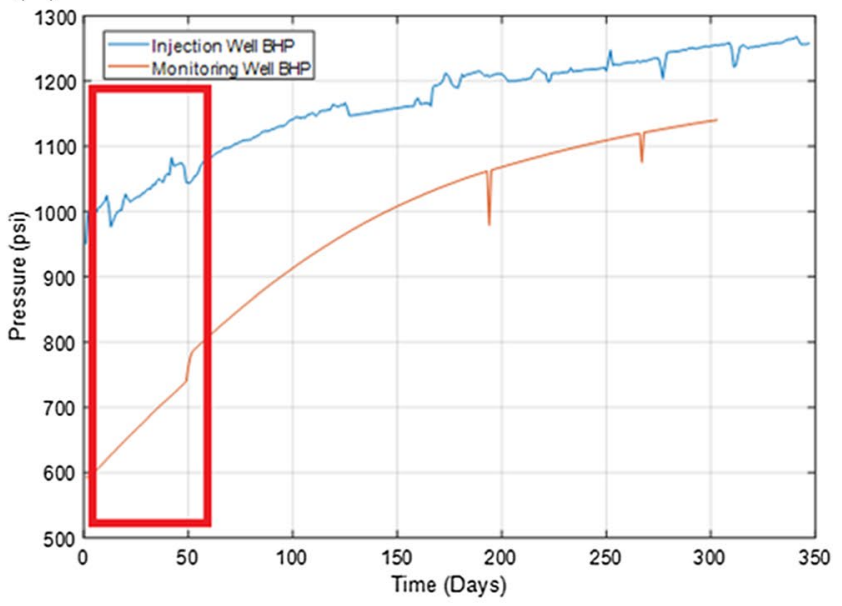

(B)

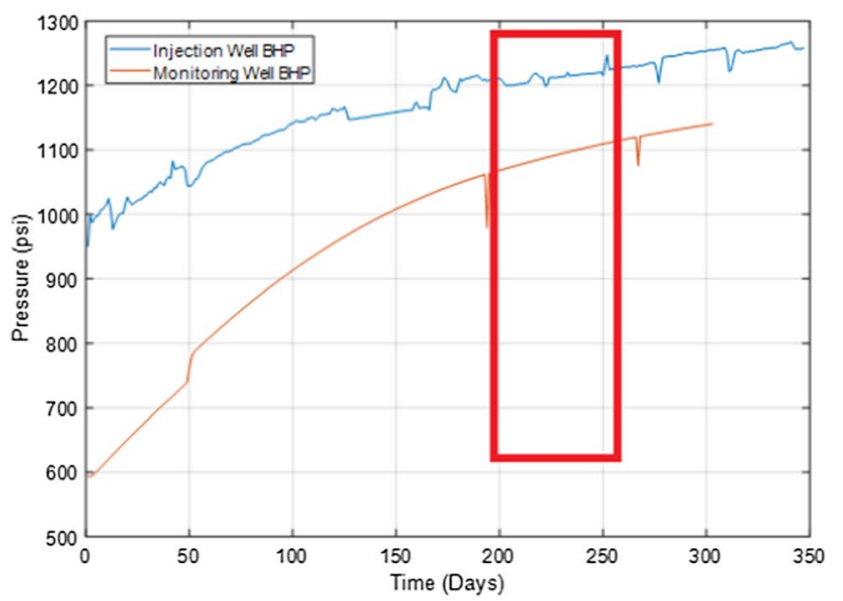

Fig. 10 Selected time intervals to estimate injectivity index for south lobe (a) at early time interval and (b) at later time interval

pressure data used for the injectivity index calculation. We used monitoring well pressure as a surrogate for average reservoir pressure and calculate injectivity index based on field data. Then, we compared the results with the calculated injectivity index using the simplified physics-based model. The estimated injectivity index using the simplified physics-based model is $9.25 \mathrm{rbbl} /($ day $\times$ psi) for the first time interval and $13.96 \mathrm{rbbl} /($ day $\times \mathrm{psi}$ ) for the second time interval. Field data show the injectivity index is 9.09 $\mathrm{rbbl} /($ day $\times \mathrm{psi}$ ) for the first time interval and $15.5 \mathrm{rbbl} /$ (day $\times$ psi) for the second time interval. The result of the comparison shows a reasonable agreement between field estimated and simplified physics-based model estimated injectivity index.

\section{Conclusion}

In this work, a simplified physics-based model is used based on the fluid continuity governing equation for estimating reservoir parameters. This method relies mainly on injector data to estimate specific reservoir parameters. The advantages of this physics-based lump parameter approach are that it requires less data and requires less computation time in comparison with the numerical simulations. The fitted parameters include the injectivity index and total fluid compressibility multiplied by pore volume. Using a simplified physics-based approach cannot replace the necessity of simulations to estimate different reservoir parameters and explain reservoir phenomena in detail, but it could provide a fast approach to estimate specific parameters that are important from operational aspects using limited data. The simplified physics-based approach also relies on the quality of the collected field data. In the case that the field data are not reliable (e.g., errors associated with the field data measurement due to gauge malfunctions) or there is time gap in the data collection (limited data recording), the model loses its accuracy and is unable to fit the response function. Although not discussed here, we applied the model to study the reservoir behavior of the northern lobe. A low R-squared estimated using multivariate model $(0.37)$ shows that the simplified model was unable to predict the reservoir behavior accurately mainly because of injection well condition in which data were collected.

The response of a synthetic numerical model was compared with the simplified physics-based model response. The fluid compressibility derived using simplified physicsbased model is in good agreement with the numerically calculated compressibility using the numerical simulator. Reservoir parameters for $\mathrm{CO}_{2}$ storage in a selected carbonate oil field were investigated in different time intervals. The comparison between predicted and field measured $\mathrm{CO}_{2}$ injection volume was used to evaluate model prediction reliability. The total compressibility times pore volume is estimated to be $2727 \mathrm{rbbl} / \mathrm{psi}$, and estimated injectivity index is $4.89 \mathrm{rbbl} /(\mathrm{day} \times \mathrm{psi})$ for the middle lobe. The total compressibility times pore volume of the southern lobe is $1310 \mathrm{rbbl} / \mathrm{psi}$, and estimated injectivity index is $7.15 \mathrm{rbbl} /($ day $\times \mathrm{psi})$. A good agreement was observed between field measured and estimated injectivity index for the middle and southern lobe injector.

Acknowledgement We would like to thank the Midwest Regional Carbon Sequestration Partnership (MRCSP) for funding this project. We thank Rick Peterson for providing management review of the article on behalf of Battelle Memorial Institute.

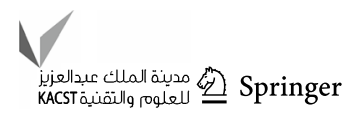




\section{Compliance with ethical standards}

\section{Conflict of interest None.}

Availability of data and material The data that support the findings of this study will be available from the corresponding author upon request.

Open Access This article is licensed under a Creative Commons Attribution 4.0 International License, which permits use, sharing, adaptation, distribution and reproduction in any medium or format, as long as you give appropriate credit to the original author(s) and the source, provide a link to the Creative Commons licence, and indicate if changes were made. The images or other third party material in this article are included in the article's Creative Commons licence, unless indicated otherwise in a credit line to the material. If material is not included in the article's Creative Commons licence and your intended use is not permitted by statutory regulation or exceeds the permitted use, you will need to obtain permission directly from the copyright holder. To view a copy of this licence, visit http://creativecommons.org/licenses/by/4.0/.

\section{References}

Albertoni A, Lake LW (2003) Inferring interwell connectivity only from well-rate fluctuations in waterfloods. SPE Reserv Eval Eng $6: 6-16$

Alvarado V, Manrique E (2010) Enhanced oil recovery: an update review. Energies 3:1529-1575

Bachu S, Bonijoly D, Bradshaw J, Burruss R, Holloway S, Christensen NP, Mathiassen OM (2007) $\mathrm{CO}_{2}$ storage capacity estimation. Methodol Gaps Int J Greenh Gas Control 1:430-443

Bastami A, Delshad M, Pourafshari P (2012a) Rapid estimation of water flooding performance and optimization in EOR by using capacitance resistive model

Bastami A, Delshad M, Pourafshary P (2012) Rapid estimation of water flooding performance and optimization in EOR by using capacitance resistive model. IranJ Chem Eng 9:3-16

Bissell R, Vasco D, Atbi M, Hamdani M, Okwelegbe M, Goldwater M (2011) A full field simulation of the In Salah gas production and $\mathrm{CO}_{2}$ storage project using a coupled geo-mechanical and thermal fluid flow simulator. Energy Procedia 4:3290-3297

Board AERC (1979) Gas well testing: theory and practice. Energy Resources Conservation Board, Calgary

Bradshaw J, Bachu S, Bonijoly D, Burruss R, Holloway S, Christensen NP, Mathiassen OM (2007) $\mathrm{CO}_{2}$ storage capacity estimation: issues and development of standards. Int J Greenh Gas Control $1: 62-68$

Catacosinos P, Harrison III W, Reynolds R, WestJohn D, Wollensack M (2000) Stratigraphic Nomenclature for Michigan: Michigan Department of Environmental Quality, Geological Survey Division, 1 sheet

CMG-GEM (2012) Advance compositional and GHG reservoir simulator user's guide. Calgary, Alberta

Coniglio M, Frizzell R, Pratt BR (2004) Reef-capping laminites in the Upper Silurian carbonate-to-evaporite transition, Michigan Basin, south-western Ontario. Sedimentology 51:653-668

Delshad M, Kong X, Tavakoli R, Hosseini SA, Wheeler MF (2013) Modeling and simulation of carbon sequestration at Cranfield incorporating new physical models. Int J Greenh Gas Control 18:463-473

Eshraghi SE, Rasaei MR, Zendehboudi S (2016) Optimization of miscible $\mathrm{CO}_{2}$ EOR and storage using heuristic methods combined with capacitance/resistance and Gentil fractional flow models. J Nat Gas Sci Eng 32:304-318
Fang Z, Khaksar A, Gibbons K (2012) Geomechanical risk assessments for $\mathrm{CO}_{2}$ sequestration in depleted hydrocarbon sandstone reservoirs. SPE Drill Compl 27:368-382

Gale J (2004) Geological storage of $\mathrm{CO}_{2}$ : What do we know, where are the gaps and what more needs to be done? Energy 29:1329-1338

Ganesh PR, Mishra S, Mawalkar S, Gupta N, Pardini R (2014) Assessment of $\mathrm{CO}_{2}$ injectivity and storage capacity in a depleted pinnacle reef oil field in northern Michigan. Energy Procedia 63:2969-2976

Gözel ME (2015) The use of capacitance-resistive models for estimation of interwell connectivity and heterogeneity in a waterflooded reservoir: a case study. Middle East Technical University, Ankara

Grammer GM, Barnes DA, Harrison III WB, Sandomierski AE, Mannes RG (2009) Practical synergies for increasing domestic oil production and geological sequestration of anthropogenic $\mathrm{CO}_{2}$ : an example from the Michigan Basin

Gupta N, Cumming L, Osborne R (2015) Importance of field projects and regional mapping to demonstrate geologic storage potential in the midwestern United States. In: Eastern section meeting, 2015

Haagsma A et al (2017) Static earth modeling of diverse Michigan Niagara Reefs and the implications for $\mathrm{CO}_{2}$ storage. Energy Procedia 114:3353-3363

Huh JMS (1974) Geology and diagenesis of the Niagaran Pinnacle Reefs in the northern shelf of the Michigan Basin

Kano Y, Ishido T (2011) Numerical simulation on the long-term behavior of $\mathrm{CO}_{2}$ injected into a deep saline aquifer composed of alternating layers. Energy Procedia 4:4339-4346

Kelley M, Abbaszadeh M, Mishra S, Mawalkar S, Place M, Gupta N, Pardini R (2014) Reservoir characterization from pressure monitoring during $\mathrm{CO}_{2}$ injection into a depleted pinnacle reefMRCSP commercial-scale CCS demonstration project. Energy Procedia 63:4937-4964

Kim JS, Lake LW, Edgar TF (2012) Integrated capacitance-resistance model for characterizing waterflooded reservoirs. IFAC Proc Vol 45:19-24

Kumar A, Noh MH, Ozah RC, Pope GA, Bryant SL, Sepehrnoori K, Lake LW (2005) Reservoir simulation of CO 2 storage in aquifers. SPE J 10:336-348

Lake LW, Liang X, Edgar TF, Al-Yousef A, Sayarpour M, Weber D (2007) Optimization of oil production based on a capacitance model of production and injection rates. In: Hydrocarbon economics and evaluation symposium, Society of Petroleum Engineers

Li P et al (2019) Screening and simulation of offshore $\mathrm{CO}_{2}$-EOR and storage: a case study for the HZ21-1 oilfield in the Pearl River Mouth Basin, Northern South China Sea. Int J Greenh Gas Control 86:66-81

Mamghaderi A, Bastami A, Pourafshary P (2013) Optimization of waterflooding performance in a layered reservoir using a combination of capacitance-resistive model and genetic algorithm method. J Energy Resourc Technol 135

Mathias SA, Gluyas JG, Oldenburg CM, Tsang C-F (2010) Analytical solution for Joule-Thomson cooling during $\mathrm{CO}_{2}$ geosequestration in depleted oil and gas reservoirs. Int J Greenh Gas Control 4:806-810

Meehan D (1980) A correlation for water compressibility. Pet Engineer 52:125-126

Miller J et al (2014) Alternative conceptual geologic models for $\mathrm{CO}_{2}$ injection in a Niagaran pinnacle reef oil field, Northern Michigan, USA. Energy Procedia 63:3685-3701

Nghiem L, Shrivastava V, Tran D, Kohse B, Hassam M, Yang C Simulation of $\mathrm{CO}_{2}$ storage in saline aquifers. In: SPE/EAGE reservoir characterization \& simulation conference, 2009

Nguyen AP (2012) Capacitance resistance modeling for primary recovery, waterflood and water- $\mathrm{CO}_{2}$ flood 
Nguyen AP, Kim JS, Lake LW, Edgar TF, Haynes B (2011a) Integrated capacitance resistive model for reservoir characterization in primary and secondary recovery. In: SPE annual technical conference and exhibition. Society of Petroleum Engineers

Nguyen AP, Lasdon L, Lake LW, Edgar TF (2011b) Capacitance resistive model application to optimize waterflood in a West Texas Field. In: SPE annual technical conference and exhibition. Society of Petroleum Engineers

Nordbotten JM, Celia MA (2010) Analysis of plume extent using analytical solutions for $\mathrm{CO}_{2}$ storage

Nordbotten JM, Celia MA, Bachu S (2005) Injection and storage of $\mathrm{CO}_{2}$ in deep saline aquifers: analytical solution for $\mathrm{CO}_{2}$ plume evolution during injection. Transp Porous Media 58:339-360

Okwen RT, Stewart MT, Cunningham JA (2010) Analytical solution for estimating storage efficiency of geologic sequestration of $\mathrm{CO}_{2}$. Int J Greenh Gas Control 4:102-107

Oruganti YD, Mishra S (2013) An improved simplified analytical model for $\mathrm{CO}_{2}$ plume movement and pressure buildup in deep saline formations. Int J Greenh Gas Control 14:49-59

Pawar RJ et al (2015) Recent advances in risk assessment and risk management of geologic $\mathrm{CO}_{2}$ storage. Int J Greenh Gas Control 40:292-311

Raziperchikolaee S, Alvarado V, Yin S (2013) Effect of hydraulic fracturing on long-term storage of $\mathrm{CO}_{2}$ in stimulated saline aquifers. Appl Energy 102:1091-1104

Raziperchikolaee S, Kelley M, Gupta N (2019) A screening framework study to evaluate $\mathrm{CO}_{2}$ storage performance in single and stacked caprock-reservoir systems of the Northern Appalachian Basin. Greenh Gases Sci Technol 9:582-605

Raziperchikolaee S, Mishra S (2019a) Numerical simulation of $\mathrm{CO}_{2}$ Huff and Puff feasibility for light oil reservoirs in the Appalachian Basin: sensitivity study and history match of a $\mathrm{CO}_{2}$ Pilot Test. Energy Fuels 33:10795-10811

Raziperchikolaee S, Mishra S (2019) Statistical learning based predictive models to assess stress changes-reservoir deformation due to $\mathrm{CO}_{2}$ sequestration into saline aquifers. Int J Greenh Gas Control $88: 416-429$

Raziperchikolaee S, Mishra S (2020) Statistical based hydromechanical models to estimate poroelastic effects of $\mathrm{CO}_{2}$ injection into a closed reservoir. Greenh Gases Sci Technol

Riley R et al. (2010) Evaluation of $\mathrm{CO}_{2}$-enhanced oil recovery and sequestration opportunities in oil and gas fields in the MRCSP Region MRCSP Phase II Topical Report October 2005 October 2010. DOE Cooperative Agreement No DOE Cooperative Agreement No

Rine M, Barnes D, Harrison WB (2015) Petrophysical and stratigraphic characterization of Michigan Silurian Reefs. In: Eastern section meeting, 2015
Rubin E, De Coninck H (2005) IPCC special report on carbon dioxide capture and storage UK: Cambridge University Press TNO (2004): Cost Curves for $\mathrm{CO}_{2}$ Storage, Part 2:14

Salehian M, Soleimani R (2018) Development of integrated capacitance resistive model for predicting waterflood performance: a study on formation damage energy sources. : Recov Utiliz Environ Effects 40:1814-1825

Sayarpour M (2008) Development and application of capacitanceresistive models to water/ $\mathrm{CO}_{2}$ floods

Sayarpour M, Kabir CS, Lake LW (2009) Field applications of capacitance-resistance models in waterfloods. SPE Reserv Eval Eng 12:853-864

Sayarpour M, Zuluaga E, Kabir CS, Lake LW (2009) The use of capacitance-resistance models for rapid estimation of waterflood performance and optimization. J Pet Sci Eng 69:227-238

Temizel C, Salehian M, Cinar M, Gok IM, Alklih MY (2018) A theoretical and practical comparison of capacitance-resistance modeling with application to mature fields. In: SPE Kingdom of Saudi Arabia annual technical symposium and exhibition. Society of Petroleum Engineers

Uddin M, Jafari A, Perkins E (2013) Effects of mechanical dispersion on $\mathrm{CO}_{2}$ storage in Weyburn $\mathrm{CO}_{2}$-EOR field-Numerical history match and prediction. Int J Greenh Gas Control 16:S35-S49

Vazquez M, Beggs HD (1977) Correlations for fluid physical property prediction. In: SPE annual fall technical conference and exhibition. Society of Petroleum Engineers

Wang W, Patzek TW, Lake LW (2011) A capacitance-resistive model and InSAR imagery of surface subsidence explain performance of a waterflood project at Lost Hills. In: SPE Annual technical conference and exhibition. Society of Petroleum Engineers,

Weber D, Edgar TF, Lake LW, Lasdon LS, Kawas S, Sayarpour M (2009) Improvements in capacitance-resistive modeling and optimization of large scale reservoirs. In: SPE western regional meeting, 2009. Society of Petroleum Engineers

Yousef AA, Lake LW, Jensen JL (2006) Analysis and interpretation of interwell connectivity from production and injection rate fluctuations using a capacitance model. In: SPE/DOE symposium on improved oil recovery, 2006. Society of Petroleum Engineers

Publisher's Note Springer Nature remains neutral with regard to jurisdictional claims in published maps and institutional affiliations. 